\title{
ANTIDIABETIC ACTIVITY OF KALANCHOE PINNATA IN ALLOXAN-INDUCED DIABETIC RATS
}

\author{
LATHA OPHELIA GEORGE ${ }^{1 *}$, RADHA HR ${ }^{2}$, SOMASHEKARAIAH BV ${ }^{3}$
}

${ }^{1}$ Department of Chemistry, Research and Development Centre, Bharathiar University, Coimbatore, Tamil Nadu, India. ${ }^{2}$ Department of Chemistry, T. John Institute of Technology, Bengaluru, Karnataka, India, ${ }^{3}$ Department of Chemistry, St. Joseph's College, Lalbagh Road, Bengaluru, Karnataka, India. Email: lathaophelia@gmail.com

Received: 08 October 2018, Revised and Accepted: 15 November 2018

ABSTRACT

Objective: The main purpose of the present study was to analyze the antidiabetic activity of methanolic extract of the leaf of Kalanchoe pinnata in alloxan-induced diabetic rats.

Methods: Diabetes mellitus (DM) is a chronic metabolic and endocrine disease regarded as a serious global public health problem. Albino Wistar rats were divided into four groups. Group I (normal) received drinking water throughout the course till 20 days. Groups II-IV received alloxan $(120 \mathrm{mg} / \mathrm{kg} \mathrm{b.w})$ i.p on the $1^{\text {st }}$ day of the study period. Group III animals received glibenclamide (10 mg/kg p.o) and Group IV received K. pinnata ( $200 \mathrm{mg} / \mathrm{kg}$ b.w p.o) for 20 days. The body weight, blood glucose level, serum urea, blood urea nitrogen (BUN), creatinine, cholesterol, total protein (TP), uric acid, and tissue (liver) antioxidant parameters: Malondialdehyde (MDA) and glutathione (GSH) were measured.

Results: K. pinnata treated rats showed the percentage increase in the body weight, decrease in the blood sugar level, creatinine, TP level, urea, uric acid, and BUN, MDA, and GSH when compared to alloxan-induced diabetic mellitus control rats. Thus, K. pinnata could be possibly employed to treat DM.

Conclusion: This preliminary analysis tested the most promising profile. It seems that methanolic extract of the leaf of $K$. pinnata improved general, blood serum, and liver antidiabetic agent. However, further studies confirming its potential is certainly warranted.

Keywords: Kalanchoe pinnata, Malondialdehyde, Alloxan, Blood urea nitrogen, Cholesterol.

(C) 2019 The Authors. Published by Innovare Academic Sciences Pvt Ltd. This is an open access article under the CC BY license (http://creativecommons. org/licenses/by/4. 0/) DOI: http://dx.doi.org/10.22159/ajpcr.2019.v12i3.30160

\section{INTRODUCTION}

Fast-growing socioeconomic development in the past 10 years has revealed a rise in the lifestyle disorders among which diabetes mellitus (DM) is growing rapidly and has turned out to be like an epidemic in many parts of the world. In 2015, DM and its associated complications affected 415 million people globally and resulted in 5 million deaths [1]. The effects of DM include long-term complications such as heart disease, stroke, dysfunction, and failure of various organs [15].

The World Health Organization (WHO) has estimated that diabetes will be one of the world's leading causes of death and disability within the next quarter century [14]. The incidence of DM is markedly increased worldwide due to modern sedentary lifestyle with consumption of junk food. Carbohydrates are the major constituents of the human diet and play an important role in energy supply [11]. DM is a major complex chronic condition that is a major source of ill health worldwide. Cardiovascular diseases, neuropathy, nephropathy, and retinopathy are among the major risks that are associated with diabetes [16]. This metabolic disorder is characterized by hyperglycemia and disturbances in carbohydrate, protein, and fat metabolism. Excessive generation of free radicals on unsaturated fatty acids has been implicated in the pathogenesis of vascular diseases and leads to increased oxidative stress [12]. According to the WHO projections, the prevalence of diabetes is such as to increase to $35 \%$ by 2020 . At present, there are over 150 million diabetics worldwide and this is likely to increase to 300 million or more by the year 2025. Statistical projection of India suggests that it is speculated to have the highest number of diabetics in the world since the number of diabetics will rise from 15 million in 1995 to 57 million in 2025. Reasons for this rise include an increase in sedentary lifestyle, consumption of energy-rich diet, obesity, and a higher life span [2]. The treatment of DM in clinical practice has been confined to the use of oral hypoglycemic agents and insulin; the former being reported being endowed with characteristic profiles of serious side effects [10]. Kalanchoe pinnata is a succulent perennial plant that grows 3-5 feet tall. It commonly known as "air plant," it has tall hollow stems, fleshy dark green leaves that are distinctively scalloped and trimmed in red, and bell-like pendulous flowers. This is employed in folk medicine for the treatment of kidney stones, gastric ulcer, pulmonary infection, rheumatoid arthritis, etc. [3]. Alloxan is toxic glucose analogs that preferentially accumulate in pancreatic beta-cells through the GLUT2 glucose transporter. In the presence of intracellular thiols, especially glutathione (GSH), alloxan generates reactive oxygen species (ROS) in a cyclic redox reaction with its reduction product, dialuric acid. Autoxidation of dialuric acid generates superoxide radicals, hydrogen peroxide, and, in a final iron-catalyzed reaction step, hydroxyl radicals. These hydroxyl radicals are ultimately responsible for the death of the beta-cells [4]. In the present study, the methanolic extract of the leaves of K. pinnata was used to evaluate its antidiabetic efficacy in alloxaninduced diabetic rats.

\section{METHODS}

Animals

Male albino Wistar rats (180-200 g) were purchased from Adita Biosys Private Limited, Tumakuru-572106, CPCSEA Reg No - 1868/ $\mathrm{Po} / \mathrm{Bt} / \mathrm{S} / 16 / \mathrm{CPCEA}$ and were maintained in the animals house of PES College of Pharmacy, Bengaluru. Once procured, animals were acclimatized for 10 days under standard husbandry conditions, the animals were housed in polypropylene cages maintained under controlled temperature at $23^{\circ} \mathrm{C} \pm 2^{\circ} \mathrm{C}$, relative humidity $45-55 \%$, and with $12: 12 \mathrm{~h}$ day/night cycle. Temperature and humidity were recorded daily. The animals had free access to standard rat pellet along with water supplied ad libitum under strict hygienic conditions. The experimental protocols were subjected to approval by the Institutional Animal Ethics Committee (IAEC approval No - PESCP/IAEC/63/2018 
dated 13-1-2018 and conducted according to CPCSEA guidelines, Government of India).

\section{Drugs and chemicals}

Glibenclamide, tris- $\mathrm{HCl}$, Ellman's reagent, thiobarbituric acid, alloxan monohydrate, blood urea nitrogen (BUN), creatinine, urea, total cholesterol (TC), uric acid, total protein (TP), etc., were used. These drugs/chemicals/kits were procured from authentic suppliers in Bengaluru. All the other chemicals used in the study were of analytical grade and the highest purity.

\section{Induction of DM in rats}

After $18 \mathrm{~h}$ of fasting in rats, stable DM was induced to Groups II-IV rats by single intraperitoneal injection of alloxan $(120 \mathrm{mg} / \mathrm{kg}$ ip $)$ dissolved in normal saline and Group I rats (vehicle control) received only the normal saline. The rats were given the standard diet $(20 \%$ glucose solution for $12 \mathrm{~h}$ to prevent initial drug-induced hypoglycemic mortality) and water ad libitum. After $72 \mathrm{~h}$ of alloxan injection, fasted blood glucose levels were estimated by the tail-tip method using glucometer. Only rats with the blood glucose level over $150 \mathrm{mg} / \mathrm{dL}$ were considered to be diabetic rats and were used for the experiment [5].

\section{Pharmacological activities}

The animals used for testing consisted of four groups. Group I (normal) received drinking water throughout the course till 20 days. Groups II-IV received alloxan $(120 \mathrm{mg} / \mathrm{kg} \mathrm{b.w})$ i.p on the $1^{\text {st }}$ day of the study period. Group III animals received from the $4^{\text {th }}$ day glibenclamide $(10 \mathrm{mg} / \mathrm{kg}$ p.o for the duration of 20 days. Group IV received from the $4^{\text {th }}$ day K. pinnata $(200 \mathrm{mg} / \mathrm{kg}$ b.w p.o) for the duration of 20 days. Fasted blood samples were collected from the tail vein for the blood glucose estimation of the $0^{\text {th }}, 10^{\text {th }}$, and $20^{\text {th }}$ days using one touch glucometer. The food and water intake was monitored daily for each rat, and the periodical differences in the body weight of the individual animals were also measured during 20 days of the experimental period.

\section{Blood sampling and serum processing}

Fasted blood samples were collected from the tail vein for the blood glucose estimation. The rats were anesthetized using light ketamine anesthesia at the dose of $40 \mathrm{mg} / \mathrm{kg}$ b.w i.p. $24 \mathrm{~h}$ after the final dosing schedule. Then, the blood was withdrawn using a capillary tube from the retro-orbital plexus. $1 \mathrm{ml}$ of blood was collected from each animal of all the groups in Eppendorf tubes. The collected blood was kept in an upright position for 30-45 min incubation to facilitate clotting and then subjected to cold centrifugation at $2000 \mathrm{rpm}$ for $20 \mathrm{~min}$. The supernatant serum was collected in another Eppendorf tube and is checked for turbidity. If turbidity is present, then again it is subjected for recentrifugation at $2000 \mathrm{rpm}$ for $10 \mathrm{~min}$. The clear serum was used for the estimation of various biochemical parameters - urea, BUN, creatinine, TC, TP, and uric acid [6].

\section{Euthanasia and liver homogenate preparation}

All experimental animals were sacrificed by overdose of thiopental sodium anesthesia (150 mg/kg b.w i.p) as per CPCEA norms. Immediately, only the liver was removed and washed with ice-cold physiological saline. The liver was done into small pieces and was homogenized using RMS tissue homogenizer in $0.1 \mathrm{M}$ tris- $\mathrm{HCl}$ buffer $\mathrm{pH} 7.4$ to give a $10 \%$ homogenate. This homogenate was used for the antioxidant parameters estimation (malondialdehyde [MDA] and GSH) [9]. The portion of the liver was treated for the histopathological observation.

\section{Estimation of serum creatinine}

Serum creatinine level was estimated using Erba Diagnostic kit. The absorbance of standard and test was read against blank at $505 \mathrm{~nm}$ or 505-670 $\mathrm{nm}$ using autoanalyzer and the concentration was noted down which appeared on the autoanalyzer.

\section{Estimation of serum cholesterol}

For the estimation of serum cholesterol, Erba Diagnostic kit was utilized. Estimation was performed by end point method. The absorbance of standard and test was read against blank at $505 \mathrm{~nm}$ or $505-670 \mathrm{~nm}$ using autoanalyzer and also the concentration which appears in autoanalyzer was noted down.

\section{Estimation of serum urea and BUN}

The estimation of serum urea was estimated utilizing Erba Diagnostic kit. The estimation was performed using fixed-time method. The absorbance of the test was read at $340 \mathrm{~nm}$ and the concentration was noted down which appeared on the semi autoanalyzer. BUN was calculated by serum urea $\times 0.467$.

\section{Estimation of serum TP}

The estimation of serum TP was estimated using Erba Diagnostic kit. The estimation was performed using end point method. The absorbance of the test was read at $546 \mathrm{~nm}$ and the concentration was noted down which appeared on the autoanalyzer.

\section{Estimation of uric acid}

The estimation of serum uric acid was estimated using Erba Diagnostic kit. The estimation was performed using end point method. The absorbance of the test was read at $546 \mathrm{~nm}$ and the concentration was noted down which appeared on the semi autoanalyzer.

\section{Estimation of lipid peroxidation}

The assay mixture method was followed according to Ohkawa et al. The reaction mixture contained $0.2 \mathrm{ml}$ of $8.1 \%$ sodium dodecyl sulfate, $1.5 \mathrm{ml}$ of $20 \%$ acetic acid solution was adjusted to $\mathrm{pH} 3.5$ by sodium hydroxide, and $1.5 \mathrm{ml}$ of $0.8 \%$ aqueous solution of thiobarbituric acid was added to $0.2 \mathrm{ml}$ of post-mitochondrial supernatant $(10 \% \mathrm{w} / \mathrm{v})$ of homogenate. The mixture was brought up to $4 \mathrm{ml}$ with distilled water and heated at $95^{\circ} \mathrm{C}$ for $60 \mathrm{~min}$, after cooling with tap water, $1 \mathrm{ml}$ distilled water, and $5 \mathrm{ml}$ of the mixture of $\mathrm{n}$-butanol and pyridine $(15: 1 \mathrm{v} / \mathrm{v})$ was added and centrifuged. The organic layer was removed and its absorbance was measured at $532 \mathrm{~nm}$ against blank using semi autoanalyzer.

\section{Estimation of GSH}

The assay mixture was followed according to the Ellman's method. To $0.1 \mathrm{ml}$ of tissue homogenate, $2.4 \mathrm{ml}$ of $0.002 \mathrm{M}$ EDTA solution was added and kept on ice bath for $10 \mathrm{~min}$. Then, $2 \mathrm{ml}$ of distilled water and $0.5 \mathrm{ml}$ of $50 \%$ trichloroacetic acid were added. The mixture was maintained at ice bath for $10-15 \mathrm{~min}$ and then centrifuged at $3000 \mathrm{rpm}$ for $15 \mathrm{~min}$. $1 \mathrm{ml}$ of supernatant was taken and $2 \mathrm{ml}$ of tris- $\mathrm{HCl}$ buffer was added followed by $0.05 \mathrm{ml}$ of DTNB solution (Ellman's reagent). A yellow color was developed read immediately at absorbance of $412 \mathrm{~nm}$ against blank using semi autoanalyzer. GSH content was calculated using extension coefficient $13.6 \times 10^{3} \mathrm{M} 1 \mathrm{~cm}^{-1}$. The values are expressed as units $/ \mathrm{mg}$ protein.

$$
\text { Calculation: } \mathrm{GSH}=\frac{\text { Absorption at } 412 \mathrm{~nm}}{\text { Extinction coefficient } \times \mathrm{TP} \times \text { total volume }}
$$

\section{Statistical analysis}

Values reported were expressed as mean \pm standard deviation. The statistical analysis was carried out using one-way analysis of variance, followed by Bonferroni method of statistics for comparison of selected pairs to compare the treatment groups with the control groups. Calculations were carried out using GraphPad Prism statistical program (version: 5.03). With all analyses, an associated $\mathrm{p}<0.0001$ was considered statistically significant.

\section{RESULTS}

\section{Effect on body weight}

In Table 1 the alloxan-induced DM rats have shown remarkable decrease in the body weight on the $20^{\text {th }}$ day when compared to normal vehicle group rats (Group I). Groups III and IV DM rats treated with glibenclamide and MLEKP showed an increase in the body weight level when compared to Group II DM control rats. The efficacy of MLEKP in increasing the body weight is more than the standard. 
Effect on blood glucose

In Table 2 the alloxan-induced DM rats (Group II) have shown significant increase in the blood glucose level on the $20^{\text {th }}$ day when compared to normal vehicle group rats (Group I). Groups III and IV DM rats treated with glibenclamide and MLEKP have shown significant decrease in the blood glucose levels when compared to Group II DM control rats.

\section{Serum urea, uric acid, and BUN}

The alloxan-induced DM rats (Group II) in Table3 have shown significant increase in the serum urea, uric acid, and BUN levels on the 20th day when compared to normal vehicle group rats (Group I). Groups III and IV DM rats treated with glibenclamide and MLEKP have shown significant decrease in the serum urea, uric acid, and BUN levels when compared to Group II DM control rats.

Serum TC, creatinine, and TP

In Table 4 the alloxan-induced DM rats (Group II) have shown notable increase in the serum TC, creatinine, and TP levels on the $20^{\text {th }}$ day when compared to normal vehicle group rats (Group I). Groups III and IV DM rats treated with glibenclamide and MLEKP have shown significant decrease in the serum TC, creatinine, and TP levels when compared to Group II DM control rats.

Tissue (liver) parameters - lipid peroxidation (MDA) and reduced GSH

In Table 5 the MDA and GSH values have shown that the alloxan-induced DM rats (Group II) have shown significant rise in the liver tissue lipid peroxidation and decrease in the reduced GSH levels on the $20^{\text {th }}$ day when compared to normal vehicle group rats (Group I). Groups III and IV DM rats treated with glibenclamide and MLEKP have shown significant decrease in the liver tissue lipid peroxidation levels and increase in the reduced GSH levels when compared to Group II DM control rats.
Histopathological studies

Normal vehicle group rats liver histology illustrated in Fig. 1 and expressed prominent nuclei of the hepatocytes, central artery, sinusoids, Kupffer cells, canaliculi, hepatic ductules, etc.

Inflammatory cells infiltration was not observed. Alloxan administrated rats in Fig. 2 resulted in the disruption of hepatocytes, steatosis to steatohepatitis, and liver fibrosis; morphological, ultrastructural lesions were observed in the lobules of the liver. DM rats administered with glibenclamide (Group III) and MLEKP (Group IV) in Figs. 3 and 4 have shown significant protection to the hepatocyte and other structural components of the liver. Only mild disruptions were observed both in Groups III and IV rats.

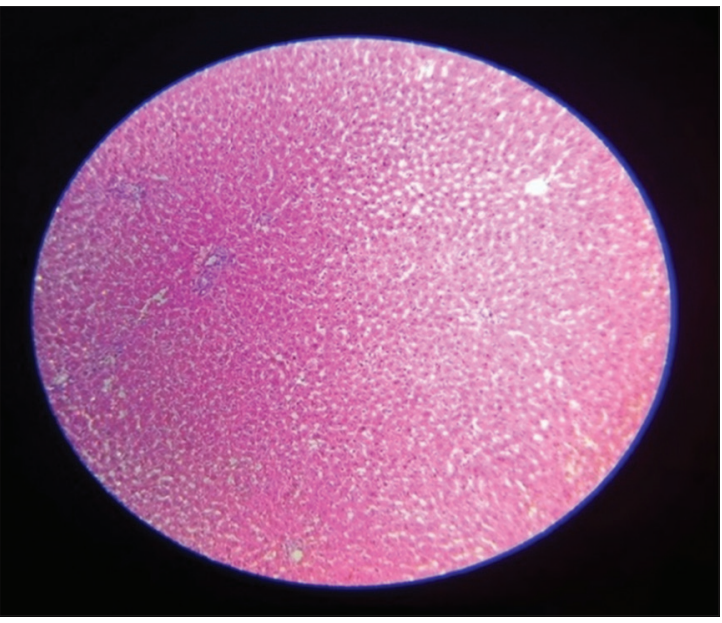

Fig. 1: Normal liver

Table 1: Effects on body weight in normal, DM, and treated DM rats

\begin{tabular}{lllll}
\hline Gp n=6 & Gp name & Initial weight $(\mathbf{g})$ & ${\text { Weight on } \text { the } \mathbf{2 0}^{\text {th }} \text { day }}^{\text {Percentage change }}$ \\
\hline I & Normal control & $182.83 \pm 6.50$ & $205 \pm 60.33$ & $12.12 \%$ increase \\
II & DM & $174.8 \pm 14.90$ & $167.33 \pm 14.50$ & $4.27 \%$ decrease \\
III & DM+Glibc & $195.16 \pm 7.14$ & $207.50 \pm 10.30$ & $6.32 \%$ increase \\
IV & DM+MLEKP & $166.66 \pm 9.90$ & $190.16 \pm 8.50$ & $14.1 \%$ increase \\
\hline
\end{tabular}

MLEKP: Methanolic leaf extract of Kalanchoe pinnata, Glibc: Glibenclamide, Gp: Group

Table 2: Effects on blood glucose in normal, DM, and treated DM rats

\begin{tabular}{llll}
\hline Gp $\mathbf{n = 6}$ & Gp name & Initial blood glucose $\mathbf{( g / d )}$ & Final blood glucose (g/dl) \\
\hline I & Normal control & $128.33 \pm 10.08$ & $137.5 \pm 7.33$ \\
II & DM & $306.16 \pm 48.2^{* * a}$ & $331.66 \pm 44.3^{* *+a}$ \\
III & DM+Glibc & $353.66 \pm 35.9$ & $174.33 \pm 15.4^{* *+6}$ \\
IV & DM+MLEKP & $328 \pm 33.70$ & $180.16 \pm 18.06^{* * b}$ \\
\hline
\end{tabular}

Table 3: Effects on serum urea, uric acid, and BUN in normal, DM, and treated DM rats

\begin{tabular}{|c|c|c|c|c|}
\hline Gp $n=6$ & Gp name & Urea (mg/dl) & Uric acid (mg/dl) & BUN (mg/dl) \\
\hline I & Normal control & $38.81 \pm 4.80$ & $1.38 \pm 0.09$ & $18.13 \pm 2.23$ \\
\hline II & DM & $60.35 \pm 2.30^{* * * a}$ & $2.23 \pm 0.008^{* * * a} a$ & $28.17 \pm 1.07^{* * *_{a}}$ \\
\hline III & $\mathrm{DM}+\mathrm{Glibc}$ & $35.54 \pm 3.13^{* * *}$ & $1.54 \pm 0.10^{* * * \mathrm{~b}}$ & $16.59 \pm 1.46^{* * * b}$ \\
\hline IV & DM+MLEKP & $39.33 \pm 3.84^{* * * b}$ & $1.53 \pm 0.09^{* * *} \mathrm{~b}$ & $18.36 \pm 1.79^{* * * \mathrm{~b}}$ \\
\hline
\end{tabular}

Table 4: Effects on serum total cholesterol, creatinine, and total protein in normal, DM, and treated DM rats

\begin{tabular}{|c|c|c|c|c|}
\hline Gp $n=6$ & Gp name & $\mathrm{TC}(\mathrm{mg} / \mathrm{dl})$ & Creatinine (mg/dl) & $\mathrm{TP}(\mathrm{mg} / \mathrm{dl})$ \\
\hline I & Normal control & $179.64 \pm 11.44$ & $0.50 \pm 0.001$ & $0.50 \pm 0.001$ \\
\hline II & DM & $242.81 \pm 31.42^{* *_{a}}$ & $0.62 \pm 0.04^{* a}$ & $2.80 \pm 0.10^{* * \mathrm{a}_{\mathrm{a}}}$ \\
\hline III & $\mathrm{DM}+\mathrm{Glibc}$ & $201.91 \pm 25.81^{* * \mathrm{~b}}$ & $0.39 \pm 0.06^{*+b}$ & $2.37 \pm 0.03^{* * b}$ \\
\hline IV & DM+MLEKP & $179.77 \pm 5.06^{* *+b}$ & $0.50 \pm 0.05^{* b}$ & $2.36 \pm 0.06^{* * * b}$ \\
\hline
\end{tabular}

TC: Total cholesterol, TP: Total protein 
Table 5: Effects on MDA and GSH in normal, DM, and treated DM rats

\begin{tabular}{llll}
\hline Gp n=6 & Gp name & $\begin{array}{l}\text { MDA nM/mg } \\
\text { protein }\end{array}$ & $\begin{array}{l}\text { GSH units } / \mathbf{m g} \\
\text { protein }\end{array}$ \\
\hline I & Normal control & $630.33 \pm 6.7028$. & $15 \pm 0.06$ \\
II & DM & $1232.89 \pm 8.44^{* * * a}$ & $11 \pm 0.04^{* * * a}$ \\
III & DM+Glibc & $963.66 \pm 14.23^{* * \mathrm{~b}}$ & $19.31 \pm 0.08^{* * * \mathrm{~b}}$ \\
IV & DM+MLEKP & $94.3 \pm 7.90^{* * * \mathrm{~b}}$ & $38.92 \pm 0.12^{* * *}$ \\
\hline
\end{tabular}

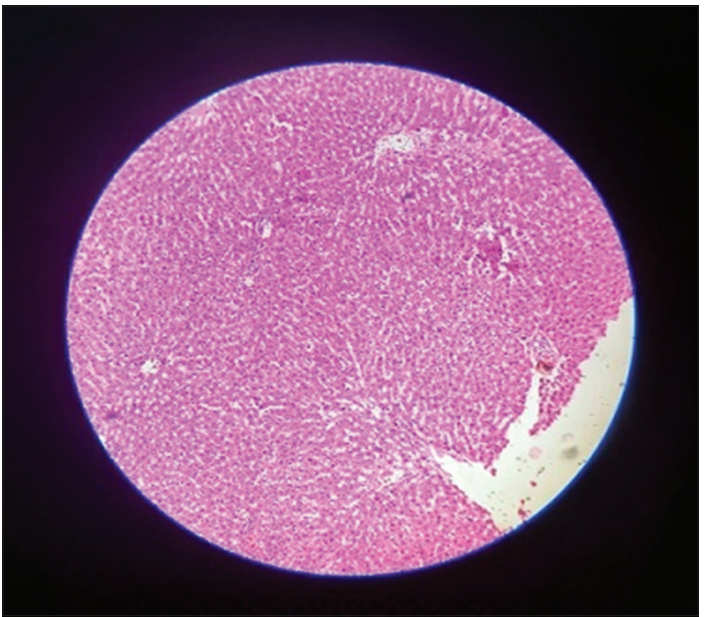

Fig. 2: Diseased liver

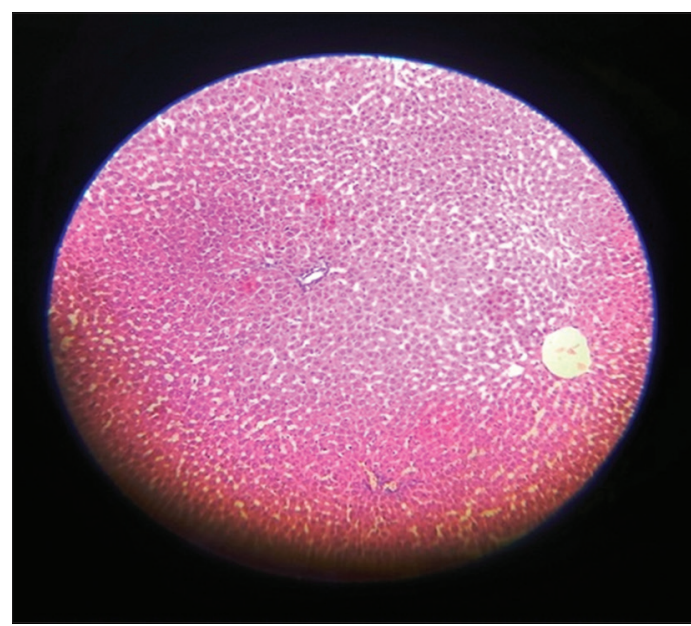

Fig. 3: Glibenclamide-treated liver

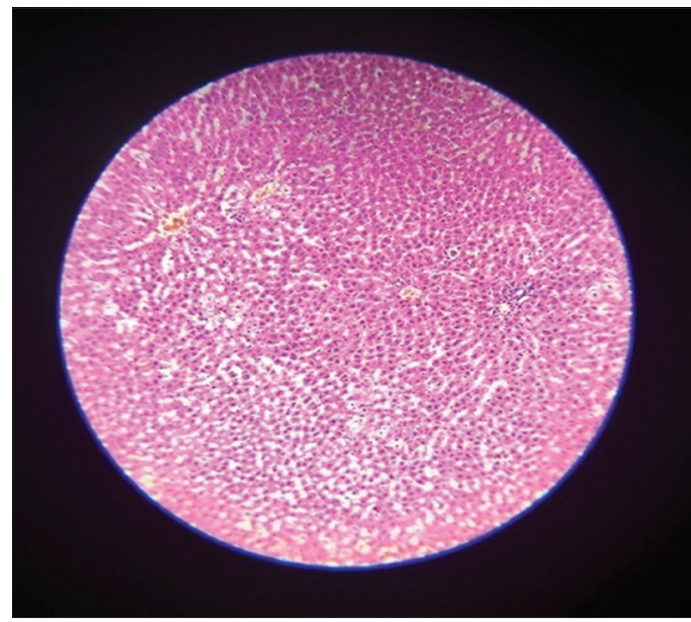

Fig. 4: MLEKP-treated liver

\section{DISCUSSION}

DM is characterized by hyperglycemia and abnormal increase in the lipid profile including TC, triglycerides, low-density lipoproteins (LDL), very LDL, and other lipoproteins. The alloxan-induced DM rats were used in the present study. DM rats (Group II) have shown significant decrease in the body weight when compared to the normal vehicle group (Group I). Alloxan-induced DM caused a significant loss in body weight while treatment with MLEKP restored the body weight. This effect of MLEKP may be due to its prevention effects on glycogenolysis, lipolysis, and gluconeogenesis. This leads to the prevention of muscle wasting and loss of tissue protein. These results confirm the efficacy of MLEKP in restoring body weight in alloxan-induced DM rats. Previous studies suggested that hyperglycemia and hyperlipidemia are the common characteristics of alloxan-induced DM in experiments rats [13]. Hyperglycemia gives rise to many complications in DM. The blood glucose levels in DM rats treated with MLEKP decrease significantly at the end of the study period when compared to normal rats, while DM control rats showed significant increase in blood sugar levels. Alloxan causes diabetes in rats by damaging the insulin-secreting beta-cells of the pancreas, leading to hyperglycemia [7]. The important phytoconstituents (including flavonoids) present in MLEKP are believed to lower the blood glucose level by promoting the glucose into the tissue cells, by stimulating the enzymes needed for the glycogenesis, and by increasing the expression of insulin receptors.

Oral administration of MLEKP produced significant beneficial effects in the lipid profile (serum TC and triglyceride) of the alloxan-induced DM rats significantly reducing serum cholesterol and triglyceride levels. These results suggest that MLEKP might be considered as a substitute for drugs to reduce complications associated with DM.

An increase in blood creatinine may indicate kidney dysfunction. The alloxan-induced DM rats have showed elevated levels of serum creatinine. MLEKP administered rats have shown significant decreased levels, suggesting protection to the kidney in alloxan-induced DM rats.

Alloxan reacts with two thio ( $\mathrm{SH}$ ) groups in the sugar binding site of glucokinase resulting in the formation of the disulfide bond and inactivation of the enzyme. As a result of alloxan reduction, dialuric acid is formed which is then reoxidized back to alloxan establishing a redox cycle for the generation of ROS and superoxide radicals [8]. The alloxan-induced DM rats have shown significant increase in the lipid peroxidation (MDA) due to oxidative stress. DM rats treated with MLEKP have shown significant decrease in the level of lipid peroxidation, indicating the effect of MLEKP in preventing the oxidative stress caused by alloxan in rats. The alloxan-induced DM rats have shown significant increase in the GSH due to oxidative stress. DM rats treated with MLEKP have shown significant increase in GSH level, indicating the effect of MLEKP in preventing the oxidative stress caused by alloxan in rats.

DM rats administered with glibenclamide (Group III) and MLEKP (Group IV) (Figs. 3 and 4) have shown significant protection to the hepatocyte and other structural components of the liver. Only mild disruptions were observed both in Groups III and IV rats.

\section{CONCLUSION}

We conclude that the methanolic extract of the leaf of $K$. pinnata has potent antioxidant and antidiabetic effect in alloxan-induced diabetic mellitus rats. The flavonoid and tannins isolated from other antidiabetic medicinal plants have been found to stimulate secretion of insulin-like effect. Further, pharmacological investigations are needed to elucidate the mechanism of the observed antidiabetic activity. The present investigation has also opened avenues for further research, especially with reference to the development of potent formulation for DM from methanolic extract of the leaf of K. pinnata.

\section{ACKNOWLEDGEMENT}

The authors thank Dr. Shivalinge Gowda KP, Professor and HOD, PES College of Pharmacy, Bangalore, for providing the facilities and support to carry out the work 


\section{AUTHORS' CONTRIBUTION}

All authors were equally involved in the manuscript framework preparation and gathering all necessary information.

\section{CONFLICTS OF INTEREST}

The authors have none to declare.

\section{REFERENCES}

1. Mehta V, Sharma A, Kailkhura P, Malairaman U. Antioxidant, antiinflammatory, and antidiabetic activity of hydroalcoholic extract of Ocimum sanctum: An in-vitro and in-silico study. Asian J Pharm Clin Res 2016;9:44-9.

2. Sikarwar MS, Patil MB. Antidiabetic activity of Pongamia pinnata leaf extracts in alloxan-induced diabetic rats. Int J Ayurveda Res 2010;1:199-204.

3. Majaz AQ, Tatiya AU, Khurshid M, Nazim S, Siraj S. The miracle plant (Kalanchoe pinnata). A phyto chemical and pharmacological review. Int J Res Ayurvada Pharm 2011;2:1478-82.

4. Ananthi J, Prakasam A, Pugalendi KV. Antihyperglycemic activity of Eclipta alba leaf on alloxan-induced diabetic rats. Yale J Biol Med 2003;76:97-102.

5. Rajaram K. Antioxidant and antidiabetic activity of Tectona grandis Linn. In alloxan induced albino rats. Asian J Pharm Clin Res 2013;6:174-7.

6. Biplav S, Sindhura G, Gowda KP. To evaluate the anti-atherosclerotic potential of quercetin in alloxan-induced diabetic rats fed with high-fat diet. Asian J Pharm Clin Res 2018;11A:379-83.

7. Ewenighi C, Dimkpa U, Onyeanusi J, Onoh L, Onoh G, Ezeugwu U. Estimation of glucose level and body weight in alloxan induced diabetic rat treated with aqueous extract of Garcinia kola seed. Ulutas Med J 2015;1:26-30

8. Cheng D, Liang B, Li Y. Antihyperglycemic effect of Ginkgo biloba extract in streptozotocin-induced diabetes in rats. BioMed Res Int 2013;2013:1-7.

9. Noori S, Nasir K, Mahboob T. Effects of cocoa powder on oxidant/ antioxidant status in liver, heart and kidney tissues of rats. J Anim Plant Sci 2009;19:174-8

10. Sireesha K, Raghunandan N. Evaluation of in vivo antidiabetic and antioxidant activity of Artocarpus hirsutus seeds in streptozotocininduced diabetic rats. Asian J Pharm Clin Res 2016;9:170-3.

11. Sivaraj S, Kannayiram G, Dasararaju G. Evaluation of antidiabetic activty of different extracts of Myristica fragrans Houtt: In vitro and in silico studies. Asian J Pharm Clin Res 2017;10:275-7.

12. Chitra V, Varma PV, Raju MV, Prakash KJ. Study of antidiabetic and free radical scavenging activity of the seed extract of Strychnos nuxvomica. Int J Pharm Pharm Sci 2010;2:106-10.

13. Venkidesh R, Mandal SC, Pal D, Lakshmi SM, Saravanakumar A. Antidiabetic activity of Smilax chinensis (L.) in alloxan induced diabetic rats. Int J Pharm Pharm Sci 2010;2:51-4.

14. Kumar MR, Kavitha K, Haldar PK. Role of herbal plants in the diabetes mellitus therapy. Int J Appl Pharm 2014;6:1-3.

15. Banerjee A, Maji B, Mukherjee S, Chaudhuri K, Seal T. In vitro antidiabetic and anti-oxidant activities of ethanol extract of Tinospora sinensis. Int J Curr Pharm Res 2017;9:42-7.

16. Tafesse TB, Hymete A, Mekonnen Y, Tadesse M. Antidiabetic activity and phytochemical screening of extracts of the leaves of Ajuga remota Benth on alloxan-induced diabetic mice. BMC Complement Altern Med 2017; 17:243 